\title{
Abnormal cardiomarkers in leukemia patients treated with allogeneic hematopoietic stem cell transplantation
}

\author{
Roziakova $\mathrm{L}^{1,2}$, Bojtarova $\mathrm{E}^{2}$, Mistrik $\mathrm{M}^{2}$, Krajcovicova $\mathrm{I}^{3}$, Mladosievicova $\mathrm{B}^{1}$ \\ Institute of Pathophysiology, School of Medicine, Comenius University, Bratislava, Slovakia. \\ lubica.roziakova@gmail.com
}

\begin{abstract}
Objective: Clinical cardiac complications in oncologic patients may develop from subclinical myocardial damage. Biomarkers N-terminal pro brain natriuretic peptide (NT-proBNP) and troponin T (cTnT) have been hypothesized to reflect preclinical cardiotoxicity earlier than echocardiography. The aim of this study was to assess prospectively the serial values of these cardiomarkers in leukemia patients treated with allogeneic hematopoietic stem cell transplantation (HSCT).

Patients: Twenty-one patients who were treated with allogeneic HSCT for acute leukemia at mean age of 32.8 years (range: 19-58) were studied. The conditioning regimen included high-dose cyclophosphamide in combination with total body irradiation (TBI) or busulphan. All patients were treated with anthracyclines earlier (median cumulative dose $250 \mathrm{mg} / \mathrm{m}^{2}$, range: $150-580$ ).

Methods: Cardiomarkers were measured before the preparative regimen (PR) and on days 1, 14 and 30 after HSCT. Their cardiac systolic function was assessed before PR, and 1-2 months after HSCT by echocardiography. Results and conslusion: The differences in NT-proBNP before PR and after HSCT were statistically significant $(p<0.001)$. The values of $c T n T$ before and after HSCT were also significantly different $(p=0.005)$. Persistent abnormalities (30 days after HSCT) of NT-proBNP levels were found in 19/21 patients $(90.5 \%$ ) and of cTnT levels in $10 / 21$ patients (47.6\%). The median cTnT concentrations were higher in patients treated with TBI than in patients without TBI $(p=0.013)$. The median NT-proBNP values were higher in patients pretreated with higher cumulative doses of anthracyclines (>250 mg/m² vs $\left.\leq 250 \mathrm{mg} / \mathrm{m}^{2}\right)$ Cardiac symptoms developed in $3 / 21$ (14.3\%) patients (Tab. 1, Fig. 3, Ref. 36). Full Text in PDF www.elis.sk.

Key words: hematopoietic stem cell transplantation, cardiotoxicity, natriuretic peptides, cardiac troponins.
\end{abstract}

Serious cardiac complications taking place in patients after therapy of leukemia may develop from subclinical myocardial damage (1-3). The cardiac status of patients treated with hematopoietic stem cell transplantation (HSCT) has been evaluated in several studies (4-9). Some authors found only low prevalence of clinical cardiotoxicity $(0.9 \%)$ in these patients (10). The greatest risk for development of cardiotoxicity is connected with previous treatment with anthracyclines (ANT) and chest irradiation (11). Moreover the patient's age, cardiac comorbidity, disease and transplant-related factors, and cardiac GvHD (graft versus host disease) may contribute to serious cardiac complications (12).

\footnotetext{
${ }^{1}$ Institute of Pathophysiology, School of Medicine, Comenius University, Bratislava, Slovakia, ${ }^{2}$ Department of Hematology and Transfusiology, University Hospital, Bratislava, Slovakia, and ${ }^{3} 1$ st Department of Oncology, School of Medicine, Comenius University, Bratislava, Slovakia

Address for correspondence: L. Roziakova, MD, PhD, Institute of Pathophysiology, School of Medicine, Comenius University, Sasinkova 4, SK81108 Bratislava, Slovakia.

Phone: +421.2.59357604, Fax: +421.2.59357601

Acknowledgements: The authors thank Marek Polomsky, M.D. from the University of Rochester, New York, USA for the revision of manuscript. This work was supported by a grant from the Scientific Grant Agency of the Ministry of Health, Slovak Republic 2007/42-UK-18, a grant from The League against the Cancer, Slovakia 2010.
}

General recommendations for monitoring the cardiotoxicity induced by HSCT have been published recently $(13,14)$. Echocardiography and radionuclide imaging techniques lack adequate sensitivity to detect early cardiac damage. The aim of this study was to assess prospectively the potential cardiotoxicity using serial values of cardiomarkers $\mathrm{N}$-terminal pro brain natriuretic peptide (NT-proBNP) and troponin T (cTnT).

\section{Patients and methods}

\section{Patients}

The study included 21 consecutive patients who received an allogeneic HSCT for acute leukemia (AL) in first or second remission from July 2009 to September 2010 at the Transplantation Centre of Hematology Department at University Hospital Bratislava. There were 12 males and 9 females with mean age of 32.8 years at HSCT (range: 19-58). Fourteen patients received peripheral-blood stem cells (PBSC) from a matched, unrelated donor while 7 patients from an HLA-identical sibling. All patients were conditioned with cyclophosphamide (CY) $60 \mathrm{mg} / \mathrm{kg}$ body weight intravenously on 2 consecutive days, in 11 patients in combination with fractionated total body irradiation (TBI) 12 Gy in six fractions of 2 Gy over 3 days, and in 9 patients in combination with peroral busulphan $4 \mathrm{mg} / \mathrm{kg}$ body weight daily for 4 days. One patient received FLAMSA-like conditioning (fludarabine $30 \mathrm{mg} / \mathrm{m}^{2}$ daily for 4 days, cytosinara- 
$159-162$

binosid $2 \mathrm{~g} / \mathrm{m}^{2}$ daily for 4 days, TBI 4 Gy in two fractions over one day, CY $60 \mathrm{mg} / \mathrm{kg}$ intravenously on 2 consecutive days, amsacrine was replaced by idarubicin $10 \mathrm{mg} / \mathrm{m}^{2}$ inravenously on 4 consecutive days). Cyclosporine A and short-term methotrexate were administered for the prophylaxis of GvHD. The study was approved by the local ethics committee of University Hospital Bratislava. Written informed consent was obtained from all patients.

One patient was previously treated for arterial hypertension, 2 patients had diabetes mellitus and 11 patients had hyperlipidemia before transplantation. One patient had a prior history of a cardiac disease because of leukemic infiltration of the heart (at the time of diagnosis of acute leukemia). The cumulative dose of ANT (idarubicin, daunorubicin and mitoxantrone) was calculated as the equivalent dose of doxorubicin. All patients were previously treated with anthracyclines (mean cumulative dose $258 \pm 120 \mathrm{mg} / \mathrm{m}^{2}$, median $250 \mathrm{mg} / \mathrm{m}^{2}$, range: $150-580$ ).

\section{Evaluation of cardiac function}

Echocardiography was performed before the preparative regimen (PR) and 1-2 months after HSCT, and the ejection fraction (EF) was calculated as a measure of left ventricular (LV) systolic function. In all patients, resting 12-lead electrocardiography (ECG) was performed the day before PR, the day after HSCT (D+1), 14 days after HSCT $(D+14), 30$ days after HSCT $(D+30)$, or in the development of clinical symptoms.

Serial measurements of plasma NT-proBNP and cTnT concentrations were performed the day before PR (baseline), the day after HSCT (D+1), 14 days after HSCT (D+14) and 30 days after HSCT $(\mathrm{D}+30)$. Venous blood samples were obtained from an indwelling catheter in the morning. Plasma concentrations of biomarkers were measured immediately by electrochemiluminescence immunoassay on Elecsys 2010 analyzer (Roche Diagnostics). Normal values of cTnT were $<0.014 \mu \mathrm{g} / \mathrm{L}$ and NT-proBNP $<100 \mathrm{pg} / \mathrm{mL}$ in males and $<150 \mathrm{pg} / \mathrm{mL}$ in females.

\section{Statistical analysis}

Continuous variables (echocardiographic parameters) are presented as mean $\pm \mathrm{SD}$ (standard deviation) and cardiac biomarkers (NT-proBNP, cTnT) as median and interquartile range. Comparisons between continuous or categorical variables were performed using the Student $t$ test and Fisher's exact test. Friedman test was used to test the difference between variables. Correlations were evaluated with Spearman correlation coefficient. A p-value less than 0.05 was considered statistically significant.

\section{Results}

Before PR, median plasma NT-proBNP value was 97.5 (59.46-244) $\mathrm{pg} / \mathrm{mL}$ (abnormal in 9 patients). After HSCT (day+1), a further increase up to 1507 (654-2788) pg/mL (abnormal in 20 patients) was observed. Fourteen days after HSCT, median plasma NT-proBNP decreased down to 710 (412-1972) $\mathrm{pg} / \mathrm{mL}$ (still abnormal in 18 patients). Persistent abnormalities were found in 19 patients 30 days after HSCT (326 (217-703) $\mathrm{pg} / \mathrm{mL})$.

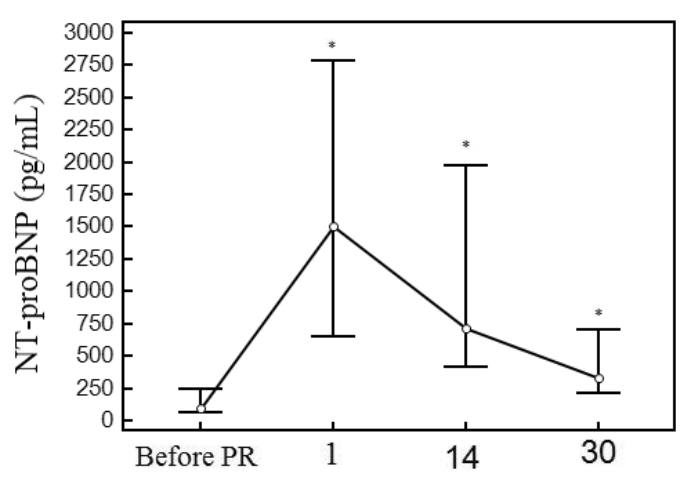

Fig. 1. Plasma NT-proBNP concentrations in the peritransplant period in acute leukemia patients. ${ }^{*} \mathbf{p}<0.001$ vs before $P R$ (preparative regimen).

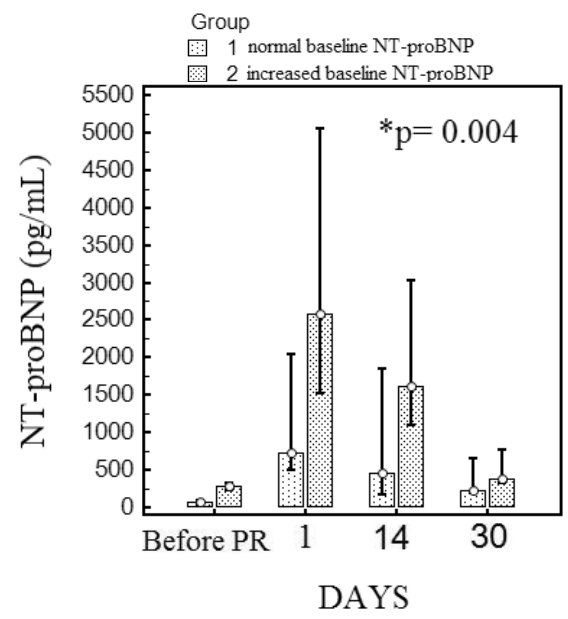

Fig. 2. Comparison of plasma NT-proBNP concentrations between two groups: normal vs increased baseline NT-proBNP values, ${ }^{*}=0.004$, PR - preparative regimen.

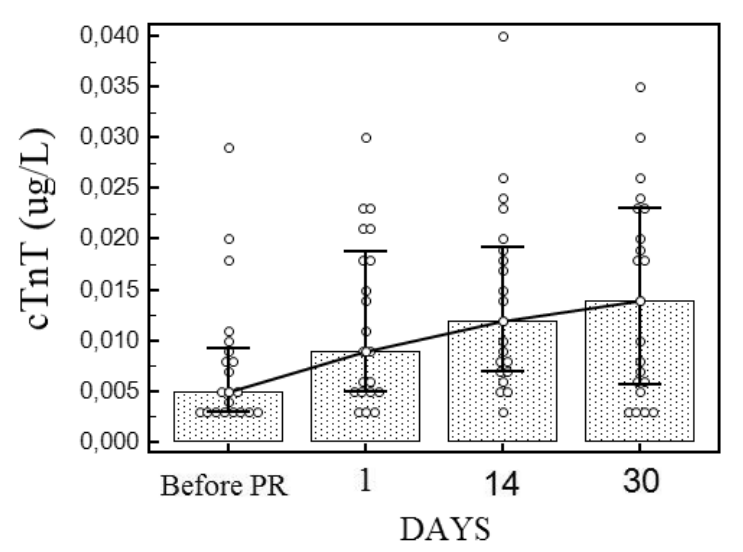

Fig. 3. Plasma cTnT levels before and after HSCT $(p=0.005)$, PR preparative regimen.

The differences in NT-proBNP before PR and after HSCT were statistically significant (Fig.1) ( $<<0.001)$. The median plasma NTproBNP values after HSCT in patients with increased baseline plasma NT-proBNP were higher than in patients with normal baseline plasma NT-proBNP, which may be associated with pretreatment of 
Tab. 1. Presentation of cardiotoxicity in patients in the peritransplant period.

\begin{tabular}{|c|c|c|c|c|c|c|c|}
\hline $\begin{array}{l}\text { Patient } \\
\text { No. }\end{array}$ & $\begin{array}{c}\text { Clinical } \\
\text { Manifestation }\end{array}$ & $\begin{array}{c}\text { Day after } \\
\text { HSCT }\end{array}$ & $\begin{array}{l}\text { Baseline NT- } \\
\text { proBNP/cTnT }\end{array}$ & $\begin{array}{l}\text { NT-proBNP/cTnT } \\
\text { after HSCT }\end{array}$ & $\mathrm{ECG}$ & PR & $\begin{array}{c}\text { CD of ANT } \\
\left(\mathrm{mg} / \mathrm{m}^{2}\right)\end{array}$ \\
\hline 1 & $\begin{array}{l}\text { chest pain, } \\
\text { dyspnoea }\end{array}$ & 3 & $237 / 0,003$ & $9589 / 0,032$ & $\begin{array}{l}\text { QTe prolongation } \\
\text { bradycardia } \\
\text { T waves inversion }\end{array}$ & $\mathrm{TBI}+\mathrm{CY}$ & 393 \\
\hline 2 & $\begin{array}{c}\text { chest pain, } \\
\text { dyspnoea }\end{array}$ & 1 & $320 / 0,008$ & $12156 / 0,076$ & $\mathrm{~T}$ waves inversion & FLAMSA & 125 \\
\hline 3 & fluid retention & 15 & $327 / 0,003$ & $3761 / 0,016$ & normal & $\mathrm{TBI}+\mathrm{CY}$ & 150 \\
\hline
\end{tabular}

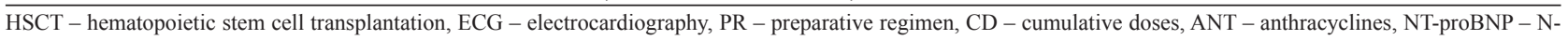
terminal pro brain natriuretic peptide, $\mathrm{cTnT}$ - cardiac troponin $\mathrm{T}$

higher cumulative doses of anthracyclines $\left(>250 \mathrm{mg} / \mathrm{m}^{2}\right.$ vs $\leq 250$ $\mathrm{mg} / \mathrm{m}^{2}, \mathrm{p}=0.004$ ) (Fig. 2). Levels of NT-proBNP showed no correlation with fever defined as the occurrence of a temperature of $>38$ ${ }^{\circ} \mathrm{C}$ in the previous week $(\mathrm{p}=-0.03, \mathrm{p}=0.77)$, with plasma creatinine level $(\mathrm{p}=0.1, \mathrm{p}=0.33)$ and arterial hypertension $(\mathrm{p}=0.08, \mathrm{p}=0.43)$.

At baseline, 3 patients presented with increased cTnT $(0.005$ $(0.003-0.009) \mu \mathrm{g} / \mathrm{L})$. After HSCT (day+1) and 14 days after HSCT, plasma cTnT values were elevated in 8 and 9 patients $(0.009$ $(0.005-0.018) \mu \mathrm{g} / \mathrm{L}$ and $0.012(0.007-0.019) \mu \mathrm{g} / \mathrm{L})$, and remained increased in 10 patients on day $30(0.014(0.005-0.023) \mu \mathrm{g} / \mathrm{L})$. The median plasma cTnT values increased with the time elapsed from HSCT (Fig. 3). The differences in cTnT before and after HSCT were significant $(\mathrm{p}=0.005)$. The changes in $\mathrm{cTnT}$ concentrations were higher in patients received TBI $(\mathrm{p}=0.013)$.

All electrocardiographic parameters of patients remained normal, except two patients. A QTc interval prolongation (497 ms), bradycardia and inversion of T waves in V1-V6 in one patient 3 days after HSCT, and inversion of T waves in V4-V6 on ECG record on first day after HSCT in the second patient were found.

In the early period after HSCT, we found a decrease in systolic LV function (LV EF 65.2 $\pm 5.6 \%$ vs $59 \pm 4.9 \%$ ), which was statistically significant $(\mathrm{p}=0.003)$. Levels of NT-proBNP showed negative correlation with LV EF ( $p=-0.35, p=0.03)$.

In the peritransplant period, three $(14.3 \%)$ patients developed clinical manifestation of cardiotoxicity (Tab. 1).

\section{Discussion}

Only few studies have assessed the detection of cardiotoxicity using BNP/NT-proBNP after HSCT (15-20) or after high dose cyclophosphamide (21). In our study, a significant rise in the plasma NT-proBNP level after HSCT $($ day +1$)$ was observed in all except one patient. This initial elevation in NT-proBNP levels may be a consequence of myocardial damage caused by the PR (TBI and/or chemotherapy). It has been reported that a preparative regimen causes an activation of endothelial cells and macrophages releasing inflammatory cytokines such as tumor necrosis factor-alpha (TNF- $\alpha$ ) or interleukins (IL) 1 and 6 (22). There is increasing evidence that inflammatory cytokines may also play an important role in the pathogenesis of heart failure by inhibiting cardiac contractility, promoting myocardial hypertrophy, and inducing cardiomyocyte apoptosis $(23,24)$.
Several studies confirmed that the administration of preparative regimen before HSCT, containing TBI and high dose $\mathrm{C} 4$ and previous anthracycline therapy may induce a subclinical myocardial injury detected by NT-proBNP $(16,20)$.

In our study, higher NT-proBNP values were found in patients pretreated with higher cumulative doses of anthracyclines. Abnormal NT-proBNP levels 14 days after HSCT were found in $85.7 \%$ of our patients. In comparison with other investigators, Horacek et al found abnormalities of this cardiomarker in $63.2 \%$ while Niwa et al in $45.6 \%(16,8)$. According to the single age-independent cut-point of $300 \mathrm{pg} / \mathrm{mL}$, we can rule out acute congestive heart failure with high probability only in $38 \%$ of patients (negative predictive value $=98 \%)(25)$.

In our study, baseline plasma cTnT levels were elevated in 3 patients, which may be associated with previous anthracycline exposure. Our results show a delayed increase in serum cTnT levels after HSCT, suggesting prolonged effects of chemoradiotherapy on the myofibrillar system of cardiomyocytes. In fact, several studies have already shown continuous damage of anthracyclines to the cardiac myofibrillar system (26-28). Kilickap et al observed in the first 3 to 5 days after administration of anthracyclines an increased cTnT level in $34 \%$ of patients (28).

The clinical value of cardiac troponins in diagnosis of cardiotoxicity during and after the anticancer treatment has been evaluated in numerous studies (28-34). Some studies have shown that elevations of serum cardiac troponins in patients after both anthracyclines and high-dose chemotherapy predicted subsequent myocardial dysfunction $(29,34)$. Only some authors have dealt with the assessment of cardiac troponins after $\operatorname{HSCT}(3,16,35$, 36). They have reported, that NT-proBNP as a marker of cardiac damage after HSCT seems to be more sensitive than cTnT. Although the role of biomarkers in relation to cardiotoxicity after HSCT was investigated serially in our study, this pilot study was limited by the small number of patients.

In conclusion, the assessment of plasma NT-proBNP and cTnT concentrations may be a useful tool for detecting the cardiac damage in leukemia patients treated with HSCT.

\section{References}

1. Monsuez JJ, Charniot JC, Vignat N, Artigou JY. Cardiac side-effects of cancer chemotherapy. Int J Cardiol 2010; 144: 3-15.

2. Roziakova L, Mladosievicova B. Cardiovascular effects after hematopoietic stem cell transplantation. Vnitr Lek 2010; 56: 233-239. 
3. Peres E, Levine JE, Khaled YA et al. Cardiac complications in patients undergoing a reduced-intensity conditioning hematopoietic stem cell transplantation. Bone Marrow Transplant 2010; 45: 149-152.

4. Tichelli A, Passweg J, Wójcik D et al. Late cardiovascular events after allogeneic hematopoietic stem cell transplantation: a retrospective multicenter study of the Late Effects Working Party of the European Group for Blood and Marrow Transplantation. Haematologica 2008; 93: 1203-1210.

5. Tichelli A, Bucher C, Rovo A et al. Premature cardiovascular disease after allogeneic hematopoietic stem cell transplantation. Blood 2007; 110 : 3463-3471.

6. Uderzo C, Pillon M, Corti P et al. Impact of cumulative anthracycline dose, preparative regimen and chronic graft-versus-host disease on pulmonary and cardiac function in children 5 years after allogeneic hematopoietic stem cell transplantation: a prospective evaluation on behalf of the EBMT Pediatric Diseases and Late Effects Working Parties. Bone Marrow Transplant 2007; 39: 667-675.

7. Kuruvilla J, Forrest DL, Lavoie JC et al. Characteristics and outcome of patients developing endocarditis following hematopoietic stem cell transplantation. Bone Marrow Transplantation 2004; 34: 969-973.

8. Fujimaki K, Maruta A, Yoshida $M$ et al. Severe cardiac toxicity in hematological stem cell transplantation: predictive value of reduced left ventricular ejection fraction. Bone Marrow Transplant 2001; 27: 307-310.

9. Armenian SH, Sun CL, Francisco L et al. Late congestive heart failure after hematopoietic cell transplantation. J Clin Oncol 2008; 26: 5537-5543.

10. Murdych T, Weisdorf DJ. Serious cardiac complications during bone marrow transplantation at the University of Minnesota, 1977-1997, Bone Marrow Transplantat 2001; 28: 283-287.

11. Perik PJ, Vries EGE, Boomsma F et al. Use of Natriuretic Peptides for Detecting Cardiac Dysfunction in Long-term Disease-free Breast Cancer Survivors. Anticancer Res 2005; 25: 3651-3657.

12. Tichelli A, Bhatia S, Socié G: Cardiac and cardiovascular consequences after haematopoietic stem cell transplantation. Br J Haematol 2008; 142: 11-26.

13. Rizzo JD, Wingard JR, Tichelli A et al. Recommended screening and preventive practices for long-term survivors after hematopoietic cell transplantation. Biol Blood Marrow Transplant 2006; 12: 138-151.

14. Coghlan JG, Handler CE, Kottaridis PD: Cardiac assessment of patients for haematopoietic stem cell transplantation. Best Pract Res Clin Haematol 2007; 20: 247-263.

15. Snowden JA, Hill GR, Hunt $P$ et al. Assessment of cardiotoxicity during haemopoietic stem cell transplantation with plasma brain natriuretic peptide. Bone Marrow Transplant 2000; 26: 309-313.

16. Horacek JM, Pudil R, Tichy M et al. Biochemical markers and assessment of cardiotoxicity during preparative regimen and hematopoietic cell transplantation in acute leukemia. Exp Oncol 2007; 29: 343-347.

17. Masuko M, Ito M, Kurasaki T et al. Plasma brain natriuretic peptide during myeloablative stem cell transplantation. Intern Med 2007; 46: 551-555.

18. Niwa N, Watanabe E, Hamaguchi M et al. Early and late elevation of plasma atrial and brain natriuretic peptides in patients after bone marrow transplantation. Ann Hematol 2001; 80: 460-465.

19. Chung T, Lim WC, Sy R, Cunningham I, Trotman J, Kritharides L. Subacute cardiac toxicity following autologous haematopoietic stem cell transplantation in patients with normal cardiac function. Heart 2008; 94: 911-918.
20. Zver S, Zadnik V, Cernelc P, Kozelj M: Cardiac toxicity of highdose cyclophosphamide and melphalan in patients with multiple myeloma treated with tandem autologous hematopoietic stem cell transplantation. Int J Hematol 2008; 88: 227-236.

21. Sandri MT, Salvatici M, Cardinale D et al. N-terminal pro-B-type natriuretic peptide after high-dose chemotherapy: a marker predictive of cardiac dysfunction? Clin Chem 2005; 51: 1405-1410.

22. Xun CQ, Thompson JS, Jennings CD, Brown SA, Widmer MB. Effect of total body irradiation, busulfan-cyclophosphamide, or cyclophosphamide conditioning on inflammatory cytokine release and development of acute and chronic graft-versus-host disease in H-2-incompatible transplanted SCID mice. Blood 1994; 83: 2360-2367.

23. Bujak M, Frangogiannis NG. The role of IL-1 in the pathogenesis of heart disease. Arch Immunol Ther Exp (Warsz) 2009; 57: 165-176.

24. Packard RR, Libby P. Inflammation in atherosclerosis: from vascular biology to biomarker discovery and risk prediction. Clin Chem 2008; 54: 24-38.

25. Januzzi JL, van Kimmenade $\mathbf{R}$, Lainchbury $\mathbf{J}$ et al. NT-proBNP testing for diagnosis and short-term prognosis in acute destabilized heart failure: an international pooled analysis of 1256 patients: the International Collaborative of NT-proBNP Study. Eur Heart J 2006; 27: 330-337.

26. Kremer LC, van der Pal HJ, Offringa M, van Dalen EC, Voute PA. Frequency and risk factors of subclinical cardiotoxicity after anthracycline therapy in children: a systematic review. Ann Oncol 2002; 13: 819-829.

27. Auner HW, Tinchon C, Linkesch W et al. Prolonged monitoring of troponin $\mathrm{T}$ for the detection of anthracycline cardiotoxicity in adults with hematological malignancies. Ann Hematol 2003; 82: 218-222.

28. Kilickap S, Barista I, Akgul E et al. CTnT can be a useful marker for early detection of anthracycline cardiotoxicity. Ann Oncol 2005; 16: 798-804.

29. Cardinale D, Sandri MT, Martinoni A et al. Left ventricular dysfunction predicted by early troponin 1 release after high-dose chemotherapy. J Am Coll Cardiol 2000; 36: 517-522.

30. Cardinale D, Sandri MT, Martinoni A et al. Myocardial injury revealed by plasma troponin I in breast cancer treated with high-dose chemotherapy. Ann Oncol 2002; 13: 710-715.

31. Cardinale D, Sandri MT, Colombo A et al. Prognostic value of Troponin I in cardiac risk stratification of cancer patients undergoing high-dose chemotherapy. Circulation 2004; 109: 2749-2754.

32. Sandri MT, Cardinale D, Zorzino L et al. Minor increases in plasma troponin I predict decreased left ventricular ejection fraction after highdose chemotherapy. Clin Chem 2003; 49: 248-252.

33. Lipshultz SE, Rifai N, Dalton VM et al. The effect of dexrazoxane on myocardial injury in doxorubicin-treated children with acute lymphoblastic leukemia. N Engl J Med 2004; 351: 145-153.

34. Auner HW, Tinchon C, Quehenberger F, Linkesch W, Sill H. Troponins in prediction of cardiotoxic effects. Lancet 2001; 357: 808.

35. Horacek JM, Tichy M, Pudil R et al. Multimarker approach to evaluation of cardiac toxicity during preparative regimen and hematopoietic cell transplantation. Neoplasma 2008; 55: 532-537.

36. Auner HW, Tinchon C, Brezinschek RI et al. Monitoring of cardiac function by serum cardiac troponin $\mathrm{T}$ levels, ventricular repolarisation indices, and echocardiography after conditioning with fractionated total body irradiation and high-dose cyclophosphamide. Eur J Haematol 2002; 69: 1-6. 